\title{
APPLICATION OF THE NATIONAL REGIME IN STATE AND MUNICIPAL PROCUREMENT
}

\author{
Iolanta V. Baltutite \\ Volgograd State University, Volgograd, Russian Federation
}

\begin{abstract}
Introduction: taking into account the political situation and the active introduction of sanctions by the European Union and Russia, the issue of applying the national regime in public procurement becomes particularly relevant. The national regime is used to develop the country's domestic economy and create the most favorable conditions for the Russian producers. The national regime is aimed at developing the economic well-being of this country and supporting the Russian commodity producer, creating the economically favorable conditions for him to participate in purchases. At the same time, the transition from the explicit ban on the state purchases of imports of certain goods to more lenient restrictions has been marked. The purpose of the study is to analyze the mechanisms of applying preferences, prohibitions and restrictions on the admission of foreign goods and persons to the state and municipal procurement. The paper examines the restrictive measures used in the procurement of foreign goods, works, and services; the provisions of preferences for goods from the countries of the Eurasian Economic Union (hereinafter also the EAEU); and compares the legislative regulation of the national regime in Russia and in foreign countries. Methods: the methods of systematization, analysis, and comparative law are used. Results: the author's well-founded position is based on the legislation and the opinion of the scientific community on the application of the national regime in the contract procurement system. The paper presents the brief conclusions and suggestions for improving the mechanism for implementing the conditions of the national regime to support the domestic suppliers for state and municipal needs. Conclusions: the national regime prescribed by part 1 of article 14 of Federal law of April 5, 2013 no. 44-FZ "On the contract system in the sphere of procurement of goods, works, and services for state and municipal needs" in practice results in significant restrictions for foreign manufacturers in many industries. Moreover, the bans, restrictions and conditions of admission apply not only to traditionally closed purchases in the field of defense and security, but also to the competitive segments of the economy, such as the supply of furniture and medicines. We have established that the introduction of a full national regime in all possible markets would not meet the interests of the majority of states. At the same time, the changes currently envisaged in the national procurement regime are aimed at simplifying the public procurement process, removing some existing prohibitions, and grouping the acts that establish the prohibitions within the national regime into a single document. However, the simplification of the national regime may jeopardize not only the work of the Russian light industry enterprises, but also the ability to independently provide the products to the main sectors of the country's industry; it will negatively affect the Russian manufacturers.
\end{abstract}

Key words: contract system of purchases, customer, government procurement, national regime, countries of the EAEU.

Citation. Baltutite I.V. Application of the National Regime in State and Municipal Procurement. Legal Concept, 2020, vol. 19, no. 1, pp. 41-50. (in Russian). DOI: https://doi.org/10.15688/lc.jvolsu.2020.1.5

УДК 347.4

Дата поступления статьи: 25.12.2019

ББК 67.402 .02

Дата принятия статьи: 20.01.2020

\section{ПРИМЕНЕНИЕ НАЦИОНАЛЬНОГО РЕЖИМА В ГОСУДАРСТВЕННЫХ И МУНИЦИПАЛЬНЫХ ЗАКУПКАХ}

\author{
Иоланта Видмантовна Балтутите
}

Волгоградский государственный университет, г. Волгоград, Российская Федерация 
Введение: с учетом политической ситуации и активным введением Европейским союзом и Россией санкций вопрос применения национального режима в государственных закупках становится особенно актуальным. Национальный режим применяется в целях развития внутренней экономики страны, формирования наиболее выгодных условий для российских производителей. Национальный режим направлен на развитие экономического благосостояния нашей страны и поддержку российского товаропроизводителя, создание ему экономически выгодных условий участия в закупках. При этом в настоящее время обозначился переход от прямого запрета на государственные закупки импорта некоторых товаров к более мягким ограничениям. Целью настоящего исследования является анализ механизмов применения преференций, запретов и ограничений на допуск иностранных товаров и лиц к государственным и муниципальным закупкам. В работе осуществлено изучение ограничительных мер, применяемых при осуществлении закупок иностранных товаров, работ, услуг; предоставление преференций товарам из стран Евразийского экономического союза; проводится сравнение законодательного регулирования национального режима в России и зарубежных странах. Методы: использованы методы системности, анализа и сравнительно-правовой. Результаты: обоснованная в работе авторская позиция опирается на законодательство и мнение научной среды по вопросу о применении национального режима в контрактной системе закупок. В статье изложены краткие выводы и предложения по совершенствованию механизма реализации условий национального режима для поддержки отечественных поставщиков для государственных и муниципальных нужд. Выводы: установленный в ч. 1 ст. 14 Федерального закона от 5 апреля 2013 г. № 44-Ф3 «О контрактной системе в сфере закупок товаров, работ, услуг для обеспечения государственных и муниципальных нужд» национальный режим на практике оборачивается для иностранных производителей существенными ограничениями во многих отраслях. Причем запреты, ограничения и условия допуска касаются не только традиционно закрытых закупок в области обороны и безопасности, но и конкурентных сегментов экономики, например поставок мебели, лекарственных препаратов. Нами установлено, что введение полного национального режима на всех возможных рынках не будет отвечать интересам большинства государств. При этом предусмотренные в настоящее время изменения в национальном режиме закупок имеют целью упростить процесс государственных закупок, убрать некоторые существующие запреты, сгруппировать акты, которые устанавливают запреты в рамках национального режима, в один документ. Однако упрощение национального режима может поставить под угрозу не только работу российских предприятий легкой промышленности, но и возможность самостоятельного обеспечения продукцией отрасли основных сфер промышленности страны; отрицательно повлияет на российских производителей.

Ключевые слова: контрактная система закупок, заказчик, государственные закупки, национальный режим, страны ЕАЭС.

Цитирование. Балтутите И. В. Применение национального режима в государственных и муниципальных закупках // Legal Concept = Правовая парадигма. - 2020. - T. 19, № 1. - C. 41-50. - DOI: https://doi.org/ 10.15688/lc.jvolsu.2020.1.5

\section{Введение}

С появлением Генерального соглашения по тарифам и торговле 1947 г. ситуация в мировой экономике постепенно начала меняться в сторону отмены ограничительных мер, принимаемых в интересах отечественных производителей [2].

Порядок применения национального режима в процессе закупок товаров, работ и услуг для государственных и муниципальных заказчиков регулируется ст. 14 Федерального закона от 5 апреля 2013 г. № 44-Ф3 «О контрактной системе в сфере закупок товаров, работ, услуг для обеспечения государственных и муниципальных нужд» [15].

На основании ч. 3-4 ст. 14 данного нормативно-правового акта Правительством РФ установлены запреты и ограничения, а Министерством финансов России определены условия допуска товаров, происходящих из иностранных государств, работ, услуг, выполняемых, оказываемых иностранными лицами.

При осуществлении заказчиками закупок товаров, которые происходят в иностранном государстве или группе иностранных государств, либо услуг, выполняемых иностранными подрядчиками, применяется национальный режим.

Правила национального режима в рамках контрактной системы закупок были предусмотрены для следующих целей:

1) поддержание российских производителей;

2) поддержание производителей из ЕАЭС;

3) запрет товаров иностранного производства двойного назначения; 
4) поддержание обороноспособности;

5) развитие российской экономики;

6) обеспечение целей национальной безопасности.

Все мероприятия, которые проводятся при государственных закупках в рамках национального режима, разделяются на три группы. Первая группа ограничений предполагает полный запрет поставки импортной продукции в рамках государственного контракта. Он, в частности, распространяется на продукцию машиностроительной отрасли, легкой промышленности, программное обеспечение, мебельную продукцию, а также на товары с оборонным предназначением. Вторая группа ограничивает допуск товаров иностранного производства. Эти правила закупок распространяются на лекарственные препараты, радиоэлектронику, медицинские изделия. Третья группа предполагает предоставление преференций для товаров российского производства.

В настоящее время во многих странах провозглашен принцип поддержки отечественного производителя. При этом опыт различных стран в области государственных закупок представляет огромный интерес для совершенствования методов организации закупок в России, а также в отношениях между странами ЕАЭС.

Так, федеральное законодательство США, регулирующее размещение государственного заказа, устанавливает приоритет для товаров, материалов любых субстанций, произведенных на территории США. Приобретение иностранных товаров возможно только в случаях невыгодности и неэффективности приобретения отечественных товаров, материалов или их отсутствия на внутреннем рынке.

В Мексике отдается предпочтение товарам отечественного производства при условии, если их цена не превышает цену иностранных товаров более чем на $15 \%$.

В Монголии тоже предусмотрены преференции отечественным производителям в размере $10 \%$ от суммы контракта (на стадии оценки заявок). Более того, несколько лет назад в стране утвержден список товаров, работ, услуг, которые должны закупаться только у отечественных производителей.

В КНР поддержка отечественных производителей представляется наиболее жест- кой. Иностранные поставщики фактически не допущены на рынок КНР, так как заказчики имеют право приобретать иностранную продукцию только в том случае, если эта продукция не производится в КНР (как мы понимаем, такую продукцию найти достаточно сложно).

Во Вьетнаме иностранные поставщики обязаны заключить отдельный договор с местным подрядчиком или субподрядчиком для участия в закупках.

В Малайзии возможно закупать иностранную продукцию только в случае, если производство этой продукции отсутствует на территории Малайзии, если местные производители не имеют соответствующего опыта и квалификации и отсутствует совместное предприятие, производящее такую продукцию. Иностранные участники закупок должны быть зарегистрированными в Центре обслуживания подрядчиков и Совете по развитию промышленности Малайзии либо (отсутствие регистрации допускается на некоторых международных закупках) должны внести тендерный депозит. Стоит добавить, что в Малайзии особые преференции в сфере закупок имеет бумипутра (этнический народ Малайзии) [9, с. 455].

Страны, входящие в Европейский союз, не вправе устанавливать приоритетный доступ своих хозяйствующих субъектов на национальный рынок в сфере закупок. Вместе с тем в рамках Союза в целом установлены меры (протекционистские) против «внешних» хозяйствующих субъектов: принцип равного доступа к закупкам и равенства участников применяется ко всем субъектам экономической деятельности, имеющим «национальность» Европейского союза, и ко всем заявкам, включая товары производства Европейского союза.

Таким образом, в странах с высокоразвитой экономикой одним из важнейших приоритетов становится создание условий и механизмов для повышения эффективности системы закупок для государственных нужд, рассматриваемой в качестве одного из стратегических инструментов обеспечения нового качества экономического роста.

Ввиду исторически сложившейся тесной связи постсоциалистических стран в настоящее время государственные (муниципальные) 
закупки являются одной из ключевых сфер, оказывающих влияние на взаимную торговлю в рамках функционирования внутреннего рынка Евразийского экономического союза.

В связи с расширением социально-экономических связей Российской Федерации со странами - членами ЕАЭС вопрос регулирования закупок в этих странах становится все более актуальным. В ч. 30 разд. III приложения № 25 Договора о Евразийском экономическом союзе установлено, что каждое из государств - членов ЕАЭС обеспечивает в отношении товаров, работ и услуг, происходящих с территорий других государств-членов, а также в отношении потенциальных поставщиков и поставщиков других государствчленов, предлагающих такие товары, работы и услуги, национальный режим в сфере закупок [3].

На вносимые в российскую контрактную систему изменения, касающиеся проведения закупок, в том числе влияющие на нормы о применении национального режима, непосредственное воздействие оказали положения Договора о Евразийском экономическом союзе, которые предусматривают необходимость обеспечения беспрепятственного доступа государств-членов к участию в закупочных процедурах, проводимых в электронном формате, путем взаимного признания электронной цифровой подписи, изготовленной в соответствии с законодательством одного государства-члена другим государством-членом. Введение положения о проведении закупок в электронной форме, безусловно, является значительным шагом на пути к сближению законодательства РФ с законодательством стран ЕАЭС и обеспечивает реализацию норм вышеуказанного Договора.

Кроме того, с начала 2018 г. хозяйствующие субъекты из стран Союза могут участвовать в процедурах закупок наравне с российскими. В этом же году Евразийский межправительственный совет одобрил распоряжение «О формировании рабочей группы высокого уровня по вопросам интеграционного взаимодействия в кооперации и импортозамещении в приоритетных отраслях промышленности» [12]. Рабочая группа создается для выработки в ЕАЭС единых подходов по реализации кооперационных и импортозамещающих проектов.
Изъятия из национального режима в соответствии с п. 31 Протокола о порядке регулирования закупок могут осуществляться на срок не более двух лет. О введении таких изъятий Россия обязана предупреждать Евразийскую экономическую комиссию, которая вправе принять обязательное для исполнения Россией решение о необходимости отмены акта об установлении изъятий [14].

Тем не менее ранее Коллегией Евразийской экономической комиссии в решении от 12 апреля 2016 г. № 31 «О признании факта нарушения Российской Федерацией обязательств, предусмотренных разделом XXII Договора о Евразийском экономическом союзе от 29 мая 2014 г., и необходимости устранения выявленного нарушения» отмечалось неисполнение Российской Федерацией обязанностей по уведомлению Евразийской экономической комиссии об изъятиях из национального режима [13].

Как справедливо отмечают В.Р. Байрашев, О.А. Беляева, подавляющее большинство актов Правительства РФ, регулирующих применение национального режима в сфере закупок, приравнивает российские товары, работы, услуги к товарам, работам, услугам из других стран ЕАЭС, что в целом позволяет говорить о соблюдении Россией Договора о ЕАЭС в части установления национального режима $[1$, с. 30$]$.

Действующий в настоящее время приказ Министерства финансов РФ предоставляет ценовые привилегии участникам госзакупок, предлагающим в своих заявках поставки из перечня товаров российского, армянского, белорусского, казахстанского и киргизского происхождения. Согласно приказу, если в закупках побеждает участник, предлагающий товар из государств - членов ЕАЭС, контракт будет заключен по предложенной им цене. Для поставщиков иностранного товара в случае их победы предусмотрены менее выгодные условия понижение на $15 \%$ цены контракта [10].

В ближайшем будущем представители стран ЕАЭС смогут принимать участие в процедурах российских государственных закупок в области обороны и безопасности.

В последнее время обсуждается вопрос относительно создания криптовалюты для осуществления взаимных расчетов между странами ЕАЭС. Для этого в первую очередь 
И.В. Балтутите. Применение национального режима в государственных и муниципальных закупках

необходимо сформировать концепцию общего финансового рынка, который должен быть запущен в ЕАЭС в 2025 году. Центральные (национальные) банки разрабатывают такую концепцию.

Договор о ЕАЭС предусматривает наличие в законодательстве стран Союза не менее двух способов обеспечения заявки на участие в госзакупках. Одним из них является банковская гарантия. Однако сейчас в России на законодательном уровне установлено ограничение на прием банковских гарантий, выдаваемых банками других государств «пятерки».

Проект Соглашения о взаимном признании банковских гарантий при осуществлении государственных закупок будет подготовлен до 1 июля 2020 года. Эта работа поручена блоку по конкуренции и антимонопольному регулированию Евразийской экономической комиссии (ЕЭК) по итогам заседания Совета ЕЭК. Документ позволит обеспечить равные условия для бизнеса государств ЕАЭС при реализации национального режима в сфере государственных закупок [4].

Следует отметить, что в настоящее время действует целый пакет нормативных актов, которыми либо установлен запрет на закупку иностранных товаров, либо определены весьма жесткие условия допуска подобных товаров на отечественный рынок. Речь идет о товарах легкой промышленности, программном обеспечении, мебели, продукции станкостроения и машиностроения. Национальный режим включает запреты, ограничения и преференции. С учетом правоприменительной практики, а также изменений рыночной ситуации и государственной политики по защите экономических интересов России такие акты периодически подлежат корректировке.

Наличие тринадцати актов, не имеющих единого порядка применения, является следствием непоследовательного правового регулирования и приводит к многочисленным ошибкам и просчетам со стороны заказчиков и поставщиков [1, с. 31].

Отсутствие единообразия в нормативных актах, регулирующих применение национального режима, безусловно препятствует полноценному развитию Закона о контрактной системе.
В 2020 г. правила применения национального режима предполагается изменить. В октябре 2019 г. был опубликован подготовленный 8 октября 2019 г. Министерством промышленности и торговли РФ проект Постановления Правительства РФ «О внесении изменений в постановление Правительства Российской Федерации от 7 марта 2019 г. № 239 и о признании утратившим силу постановления Правительства Российской Федерации от 14 января 2017 г. № 9 “Об установлении запрета на допуск товаров, происходящих из иностранных государств, работ (услуг), выполняемых (оказываемых) иностранными лицами, для целей осуществления закупок товаров, работ (услуг) для нужд обороны страны и безопасности государства"», в котором прописаны новые правила национального режима [11].

В проекте постановления предлагается изменить некоторые его правила, в частности - оставить существующий запрет только на закупки тех товаров станкоинструментальной промышленности, которые будут использоваться в целях защиты обороны и безопасности страны. Сейчас запрет на поставки импортных промышленных товаров предусмотрен в Постановлении Правительства РФ от 7 марта 2019 г. № 239 «Об установлении запрета на допуск отдельных видов товаров станкоинструментальной промышленности, происходящих из иностранных государств, для целей осуществления закупок для нужд обороны страны и безопасности государства» [8].

Таким образом, если заказчик закупает товары для собственных нужд, то на его закупки запреты не будут распространяться. Запрет будет действовать только на закупки в целях защиты обороны и безопасности страны. В остальных случаях будет применяться принцип «третий лишний» и ценовые преференции. Принцип «третий лишний» означает, что если в торгах участвуют хотя бы две компании, предлагающие российскую продукцию, то заказчик отклонит заявки, в которых предлагается поставка импортных товаров.

В результате реализации нового Постановления Правительства утратят силу постановления № 656 от 2014 г. о запретах на закупку товаров машиностроения [5], № 791 от 2014 г. о товарах легкой промышленности [6], 
№ 1119 от 2018 г. об ограничениях спортивного оружия, патронов и боеприпасов [7].

Также в проекте Постановления предусмотрена возможность закупки товаров, происходящих из иностранных государств, в случае, когда производство таких товаров на территории РФ отсутствует. При этом подтверждением исключения из установленного запрета будет считаться разрешение Минпромторга России о закупке происходящего из иностранного государства товара.

В проекте Постановления предусмотрено, что подтверждением производства продукции на территории России будут являться сведения из реестра российской промышленной продукции, а подтверждением производства промышленной продукции на территории ЕАЭС - сведения из реестра промышленной продукции, произведенной на территории государства - члена ЕАЭС.

Кроме того, должен быть создан единый реестр радиоэлектронной продукции, происходящей из государств - членов Евразийского экономического союза, за исключением РФ. Соответственно, заказчики при проведении закупок должны будут проверять наличие необходимой им техники как в реестре российской радиоэлектронной продукции, так и в реестре продукции из стран ЕАЭС.

Важнейшим элементом любой закупочной системы является ее информационная открытость. В каждой стране есть свой источник опубликования сообщений о закупках, как правило - это сайт в сети Интернет. Так, в России на таком сайте размещается информация о проведении как государственных (муниципальных), так и корпоративных закупок. Функционирование единой информационной системы обеспечивается также работой восьми электронных площадок и одной специализированной электронной площадки.

Согласно Договору о ЕАЭС, должна быть подготовлена информационная открытость и прозрачность государственных закупок. В настоящее время обеспечивается публикация информации на национальных веб-порталах стран - участниц ЕАЭС, но единая база, конечно, отсутствует.

Казначейство должно будет контролировать соблюдение правил национального режима при исполнении контрактов.
С 1 января 2020 г. заказчик при заключении контракта должен направлять в реестр контрактов информацию о стране происхождения товара, если при закупке были предусмотрены условия, запреты или ограничения допуска. Казначейство должно проверять соответствие этой информации условиям контракта как на момент его заключения, так и на момент исполнения. Если наименование страны происхождения, направленное заказчиком, не соответствует условиям контракта, то результат проверки будет отрицательным, сведения в реестр контрактов не включат.

\section{Выводы}

Статья 14 Федерального закона от 5 апреля 2013 г. № 44-Ф3 «О контрактной системе в сфере закупок товаров, работ, услуг для обеспечения государственных и муниципальных нужд» устанавливает действие национального режима при закупках товаров, работ и услуг. Действие данного режима распространяется на заказчиков, которые покупают товары, работы и услуги через конкурс, аукцион, запрос предложений и котировок. В постановлениях правительства РФ конкретизируется перечень товаров, на которые распространяется запрет или ограничительные меры.

В настоящее время установлено практически полное равенство государств - членов ЕАЭС в вопросах участия в государственных (муниципальных) закупках, а любые исключения должны либо вписываться в общие исключения Договора о ЕАЭС (ст. 29 Договора о ЕАЭС), либо оформляться в соответствии с п. 31 Протокола о порядке регулирования закупок.

Механизм импортозамещения складывается из множества нормативно-правовых актов, устанавливающих различные подходы и порядки его использования, в связи с этим заказчики и предприниматели сталкиваются с трудностями при его применении. Наличие большого количества актов, не имеющих единого порядка применения, является следствием непоследовательного правового регулирования и приводит к многочисленным ошибкам и просчетам со стороны заказчиков и поставщиков.

С 2020 г. предполагается вводить запрет на закупку иностранной продукции только в целях защиты обороны и безопасности стра- 
ны, а в остальных случаях заказчику предстоит использовать механизм отстранения от участия поставщика иностранных товаров, если есть как минимум два предложения от поставщиков российской продукции.

Данные меры имеют целью упростить процесс государственных закупок и сгруппировать акты, которые устанавливают запреты в рамках национального режима, в один документ. В законопроект добавили пищевое оборудование, музыкальные инструменты, спортивные и детские товары, строительные материалы.

Однако упрощение национального режима может поставить под угрозу не только работу российских предприятий легкой промышленности, но и возможность самостоятельного обеспечения продукцией отрасли основных сфер промышленности страны; отрицательно повлияет на российских производителей, а при возможности закупок иностранного программного обеспечения в государственные органы и вовсе будет угрожать безопасности страны.

\section{СПИСОК ЛИТЕРАТУРЫ}

1. Байрашев, В. Р. Проблемы применения национального режима в государственных и муниципальных закупках в контексте международных обязательств Российской Федерации / В. Р. Байрашев, О. А. Беляева // Журнал предпринимательского и корпоративного права. - 2019. - № 3. - С. 29-37.

2. Генеральное соглашение по тарифам и торговле (ГАТТ 1947) // Собрание законодательства РФ. 2012. - 10 сент. (№ 37, прил. ч. VI). - С. 2916-2991.

3. Договор о Евразийском экономическом союзе от 29 мая 2014 г. // Евразийская экономическая комиссия : [офиц. сайт]. - Электрон. текстовые дан. Режим доступа: http://www.eurasiancommission.org/ (дата обращения: 15.12.2019). - Загл. с экрана.

4. ЕЭК готовит проект Соглашения о взаимном признании банковских гарантий государствами ЕАЭС // Евразийская экономическая комиссия : [офиц. сайт]. - Электрон. текстовые дан. - Режим доступа: http://www.eurasiancommission.org/ru/nae/ news/Pages/19-08-2019-1.aspx (дата обращения: 15.12.2019). - Загл. с экрана.

5. Постановление Правительства РФ от 14 июля 2014 г. № 656 «Об установлении запрета на допуск отдельных видов товаров машиностроения, происходящих из иностранных государств, для целей осуществления закупок для обеспечения государственных и муниципальных нужд» // Собрание законодательства Российской Федерации. - 2014. 21 июля (№ 29). - Ст. 4157.

6. Постановление Правительства РФ от 11 августа 2014 г. № 791 «Об установлении запрета на допуск товаров легкой промышленности, происходящих из иностранных государств, и (или) услуг по прокату таких товаров в целях осуществления закупок для обеспечения федеральных нужд, нужд субъектов Российской Федерации и муниципальных нужд» // Собрание законодательства Российской Федерации. - 2014. - 25 авг. (№ 34). - Ст. 4660.

7. Постановление Правительства РФ от 20 сентября 2018 г. № 1119 «Об ограничениях допуска оружия спортивного огнестрельного с нарезным стволом, патронов и боеприпасов прочих и их деталей, происходящих из иностранных государств, для целей осуществления закупок для обеспечения государственных и муниципальных нужд» // Собрание законодательства Российской Федерации. - 2018. 1 окт. (№ 40). - Ст. 6124.

8. Постановление Правительства РФ от 7 марта 2019 г. № 239 «Об установлении запрета на допуск отдельных видов товаров станкоинструментальной промышленности, происходящих из иностранных государств, для целей осуществления закупок для нужд обороны страны и безопасности государства». - Электрон. текстовые дан. - Режим доступа: https://fas.gov.ru/documents/684829 (дата обращения: 15.12.2019). - Загл. с экрана.

9. Предпринимательское право России: итоги, тенденции и пути развития : монография / Е. Г. Афанасьева, А. В. Белицкая, В. А. Вайпан [и др.] ; отв. ред. Е. П. Губин. - М. : Юстицинформ, 2019. - 664 с.

10. Приказ Минфина России от 04.06.2018 № 126н «Об условиях допуска товаров, происходящих из иностранного государства или группы иностранных государств, для целей осуществления закупок товаров для обеспечения государственных и муниципальных нужд». - Электрон. текстовые дан. Режим доступа: pravo.gov.ru. - Загл. с экрана.

11. Проект Постановления Правительства Российской Федерации «О внесении изменений в постановление Правительства Российской Федерации от 7 марта 2019 г. № 239 и о признании утратившим силу постановления Правительства Российской Федерации от 14 января 2017 г. № 9 “Об установлении запрета на допуск товаров, происходящих из иностранных государств, работ (услуг), выполняемых (оказываемых) иностранными лицами, для целей осуществления закупок товаров, работ (услуг) для нужд обороны страны и безопасности"». - Электрон. текстовые дан. - Режим доступа: https:// regulation.gov.ru/ (дата обращения: 15.12.2019). Загл. с экрана. 
12. Распоряжение Евразийского межправительственного совета от 27.07.2018 № 10 «О формировании рабочей группы высокого уровня по вопросам интеграционного взаимодействия в кооперации и импортозамещении в приоритетных отраслях промышленности» // Евразийский экономический союз : [офиц. сайт]. - Электрон. текстовые дан. Режим доступа: http://eaeunion.org/ (дата обращения: 15.12.2019). - Загл. с экрана.

13. Решение Коллегии Евразийской экономической комиссии от 12.04.2016 № 31 «О признании факта нарушения Российской Федерацией обязательств, предусмотренных разделом XXII Договора о Евразийском экономическом союзе от 29 мая 2014 года, и необходимости устранения выявленного нарушения» // Евразийский экономический союз : [офиц. сайт]. - Электрон. текстовые дан. Режим доступа: http://www.eaeunion.org/ (дата обращения: 15.12.2019). - Загл. с экрана.

14. Решение Совета Евразийской экономической комиссии от 23.11.2015 № 69 «Об утверждении Порядка рассмотрения Евразийской экономической комиссией уведомлений государств - членов Евразийского экономического союза о принятии актов об установлении государствами-членами изъятий из национального режима в сфере государственных (муниципальных) закупок, обращений государств-членов по вопросам отмены таких актов, а также принятия Комиссией решений о необходимости отмены таких актов» // Евразийский экономический союз : [офиц. сайт]. - Электрон. текстовые дан. - Режим доступа: http://www.eaeunion. org/ (дата обращения: 15.12.2019). - Загл. с экрана.

15. Федеральный закон от 05.04.2013 № 44-Ф3 «О контрактной системе в сфере закупок товаров, работ, услуг для обеспечения государственных и муниципальных нужд» // Собрание законодательства РФ. -2013. - 8 апр. (№ 14). - Ст. 1652.

\section{REFERENCES}

1. Bajrashev V.R., Belyaeva O.A. Problemy primeneniya natsionalnogo rezhima $v$ gosudarstvennykh i munitsipalnykh zakupkakh $\mathrm{v}$ kontekste mezhdunarodnykh obyazatelstv Rossiyskoy Federatsii [Problems of Applying the National Regime in State and Municipal Procurement in the Context of International Obligations of the Russian Federation]. Zhurnal predprinimatelskogo i korporativnogo prava [Journal of Business and Corporate Law], 2019, no. 3, pp. 29-37.

2. Generalnoe soglashenie po tarifam i torgovle (GATT 1947) [General Agreement on Tariffs and Trade (GATT 1947)]. Sobranie zakonodatelstva RF [Collection of Legislation of the Russian Federation], 2012, 10 Sept. (no. 37, pril., ch. VI), pp. 2916-2991.
3. Dogovor o Evraziyskom ekonomicheskom soyuze ot 29 maya 2014 g. [Treaty on the Eurasian Economic Union of May 29, 2014]. Ofitsialnyy sayt Evraziyskoy ekonomicheskoy komissii [Official Website of the Eurasian Economic Commission]. URL: http://www.eurasiancommission.org/ (accessed 15 December 2019).

4. EEK gotovit proekt Soglasheniya o vzaimnom priznanii bankovskikh garantiy gosudarstvami EAES [The EEC is Preparing a Draft Agreement on Mutual Recognition of Bank Guarantees by the EAEU States]. Evraziyskaya ekonomicheskaya komissiya [Eurasian Economic Commission]. URL: http://www. eurasiancommission.org/ru/nae/news/Pages/19-082019-1.aspx (accessed 15 December 2019).

5. Postanovlenie Pravitelstva RF ot 14 iyulya 2014 g. № 656 «Ob ustanovlenii zapreta na dopusk otdelnykh vidov tovarov mashinostroeniya, proiskhodyashchikh iz inostrannykh gosudarstv, dlya tseley osushchestvleniya zakupok dlya obespecheniya gosudarstvennykh i munitspalnykh nuzhd» [The RF Government Decree of July 14, 2014 no. 656 "About Establishment of a Ban on the Admission of Certain Goods Machinery, Originating from Foreign States for the Purposes of Procurement for State and Municipal Needs"]. Sobranie zakonodatelstva Rossiyskoy Federatsii [Collection of Legislation of the Russian Federation], 2014, 21 June (no. 29), art. 4157.

6. Postanovlenie Pravitelstva RF ot 11 avgusta 2014 g. № 791 «Ob ustanovlenii zapreta na dopusk tovarov legkoy promyshlennosti, proiskhodyashchikh iz inostrannykh gosudarstv, i (ili) uslug po prokatu takikh tovarov v tselyakh osushchestvleniya zakupok dlya obespecheniya federalnykh nuzhd, nuzhd subyektov Rossiyskoy Federatsii i munitsipalnykh nuzhd» [The Decree of the RF Government dated 11 August 2014 no. 791 "About Establishment of a Ban on the Admission of Light Industry Goods Originating from Foreign States and (or) Services Rental of Such Goods for the Purposes of Implementation of Purchases for Ensuring Federal Needs, Needs of Subjects of the Russian Federation and Municipal Needs"]. Sobranie zakonodatelstva Rossiyskoy Federatsii [Collection of Legislation of the Russian Federation], 2014, 25 Aug. (no. 34), art. 4660.

7. Postanovlenie Pravitelstva RF ot 20 sentyabrya 2018 g. № 1119 «Ob ogranicheniyakh dopuska oruzhiya sportivnogo ognestrelnogo s nareznym stvolom, patronov i boepripasov prochikh $\mathrm{i}$ ikh detaley, proiskhodyashchikh iz inostrannykh gosudarstv, dlya celey osushchestvleniya zakupok dlya obespecheniya gosudarstvennykh i munitsipalnykh nuzhd» [Resolution of the Government of the Russian Federation of September 20, 2018 no. 1119 "On Restrictions on the Admission of Sports Firearms with a Rifled Barrel, Cartridges and Other 
Ammunition and Their Parts Originating from Foreign Countries for the Purposes of Procurement for State and Municipal Needs"]. Sobranie zakonodatelstva Rossiyskoy Federatsii [Collection of Legislation of the Russian Federation], 2018, Oct. 1 (no. 40), art. 6124.

8. Postanovlenie Pravitelstva RF ot 7 marta 2019 g. № 239 «Ob ustanovlenii zapreta na dopusk otdelnykh vidov tovarov stankoinstrumentalnoy promyshlennosti, proiskhodyashchikh iz inostrannykh gosudarstv, dlya tseley osushchestvleniya zakupok dlya nuzhd oborony strany $i$ bezopasnosti gosudarstva» [Resolution of the Government of the Russian Federation of March 7, 2019 no. 239 "On Establishing a Ban on the Admission of Certain Types of Goods of the Machine Tool Industry Originating from Foreign Countries for the Purposes of Procurement for the Needs of the Country's Defense and State Security"]. URL: https://fas.gov.ru/ documents/684829 (accessed 15 December 2019).

9. Afanaseva E.G., Beliczkaya A.V., Vajpan V.A., et al. Predprinimatelskoe pravo Rossii: itogi, tendentsii i puti razvitiya: monografiya [Business Law of Russia: Results, Trends and Ways of Development. Monograph ]. Moscow, Yustitsinform Publ., 2019. 664 p.

10. Prikaz Minfina Rossii ot 04.06.2018 № 126 n «Ob usloviyakh dopuska tovarov, proiskhodyashchikh iz inostrannogo gosudarstva ili gruppy inostrannykh gosudarstv, dlya tseley osushchestvleniya zakupok tovarov dlya obespecheniya gosudarstvennykh $i$ munitspalnykh nuzhd» [Order of the Ministry of Finance of the Russian Federation of June 4, 2018 no. 126H "On the Conditions for Admission of Goods Originating from a Foreign State or Group of Foreign States for the Purpose of Purchasing Goods for State and Municipal Needs"]. URL: pravo.gov.ru.

11. Proekt Postanovleniya Pravitelstva Rossiyskoy Federatsii "O vnesenii izmeneniy $v$ postanovlenie Pravitelstva Rossiyskoy Federatsii ot 7 marta 2019 g. № 239 i o priznanii utrativshim silu postanovleniya Pravitelstva Rossiyskoy Federatsii ot 14 yanvarya 2017 g. № 9 "Ob ustanovlenii zapreta na dopusk tovarov, proiskhodyashchikh iz inostrannykh gosudarstv, rabot (uslug), vypolnyaemykh (okazyvaemykh) inostrannymi litsami, dlya tseley osushchestvleniya zakupok tovarov, rabot (uslug) dlya nuzhd oborony strany $i$ bezopasnosti" " [Draft Resolution of the Government of the Russian Federation "On Amendments to Resolution of the Government of the Russian Federation of March 7, 2019 no. 239 and on Invalidation of Resolution of the Government of the Russian Federation of January 14, 2017 no. 9 "On Establishing a Ban on the Admission of Goods Originating from Foreign Countries, Works (Services) Performed (Rendered) by Foreign Persons for the Purpose of
Purchasing Goods, Works (Services) for the Needs of National Defense and Security"]. URL: https:// regulation.gov.ru/ (accessed 15 December 2019).

12. Rasporyazhenie Evraziyskogo mezhpravitelstvennogo soveta ot 27.07.2018 № 10 «O formirovanii rabochey gruppy vysokogo urovnya po voprosam integratsionnogo vzaimodeystviya $\mathrm{V}$ kooperatsii i importozameshchenii v prioritetnykh otraslyakh promyshlennosti» [Order of the Eurasian Intergovernmental Council of Jule 27, 2018 no. 10 "On the Formation of a High-Level Working Group on Integration Cooperation in Cooperation and Import Substitution in Priority Industries"]. Ofitsialnyy sayt Evraziyskogo ekonomicheskogo soyuza [Official Website of the Eurasian Economic Union]. URL: http:/ /eaeunion.org/ (accessed 15 December 2019).

13. Reshenie Kollegii Evraziyskoy ekonomicheskoy komissii ot 12.04.2016 № 31 «O priznanii fakta narusheniya Rossiyskoy Federatsiey obyazatelstv, predusmotrennykh razdelom XXII Dogovora o Evraziyskom ekonomicheskom soyuze ot 29 maya 2014 goda, i neobkhodimosti ustraneniya vyyavlennogo narusheniya» [Decision of the Board of the Eurasian Economic Commission of April 12, 2016 no. 31 "On Recognition of the Fact of Violation by the Russian Federation of the Obligations Provided for in Section XXII of the Treaty on the Eurasian Economic Union of May 29, 2014, and the Need to Eliminate the Detected Violation"]. Ofitsialnyy sayt Evraziyskogo ekonomicheskogo soyuza [Official Website of the Eurasian Economic Union]. URL: http://www. eaeunion.org/ (accessed 15 December 2019).

14. Reshenie Soveta Evraziyskoy ekonomicheskoy komissii ot 23.11.2015 № 69 «Ob utverzhdenii Poryadka rassmotreniya Evraziyskoy ekonomicheskoy komissiey uvedomleniy gosudarstv - chlenov Evraziyskogo ekonomicheskogo soyuza o prinyatii aktov ob ustanovlenii gosudarstvami-chlenami izyatiy iz natsionalnogo rezhima $\mathrm{v}$ sfere gosudarstvennykh (munitsipalnykh) zakupok, obrashcheniy gosudarstvchlenov po voprosam otmeny takikh aktov, a takzhe prinyatiya Komissiey resheniy o neobkhodimosti otmeny takikh aktov» [Decision of the Council of the Eurasian Economic Commission of November 23, 2015 no. 69 "On Approval of the Procedure for Consideration by the Eurasian Economic Commission of Notifications of Member States of the Eurasian Economic Union on the Adoption of Acts on the Establishment by Member States of Exemptions from the National Regime in the Field of State (Municipal) Procurement, Appeals of Member States on the Cancellation of Such Acts, as well as Decisions by the Commission on the Need to Cancel Such Acts"]. Ofitsialnyy sayt Evraziyskogo ekonomicheskogo soyuza [Official Website of the Eurasian Economic 
Union]. URL: http://www.eaeunion.org/ (accessed 15 December 2019).

15. Federalnyy zakon ot 05.04.2013 № 44-FZ «O kontraktnoy sisteme v sfere zakupok tovarov, rabot, uslug dlya obespecheniya gosudarstvennykh i munitsipalnykh nuzhd» [Federal Law ofAril 5, 2013 no. $44-$ FZ "On the Contract System in the Field of Procurement of Goods, Works, Services for State and Municipal Needs"]. Sobranie zakonodatelstva $R F$ [Collection of Legislation of the Russian Federation], 2013, April 8 (no. 14), art. 1652.

\section{Information About the Author}

Iolanta V. Baltutite, Candidate of Sciences (Jurisprudence), Associate Professor, Department of Civil and Private International Law, Base Department of the Southern Scientific Centre of the Russian Academy of Sciences, Volgograd State University, Prosp. Universitetsky, 100, 400062 Volgograd, Russian Federation, u938om@yandex.ru, https://orcid.org/0000-0001-5443-2157

\section{Информация об авторе}

Иоланта Видмантовна Балтутите, кандидат юридических наук, доцент кафедры гражданского и международного частного права (базовая кафедра ЮНЦ РАН), Волгоградский государственный университет, просп. Университетский, 100, 400062 г. Волгоград, Российская Федерация, u938om@yandex.ru,https://orcid.org/0000-0001-5443-2157 